\title{
Experimental Study on the Removal of Algae and Odor with the Combined Process of Potassium Permanganate and Powdered Activated Carbon
}

\author{
Feng-ping $\mathrm{HU}^{*}$ \\ School of Civil Engineering and Architecture. East China \\ Jiao Tong University \\ ECJTU \\ Nan Chang, China \\ hufengping22@126.com \\ Xiao-jun PENG \\ School of Civil Engineering and Architecture. East China \\ Jiao Tong University \\ ECJTU \\ Nan Chang, China \\ 763959550@qq.com
}

\author{
Wen-jie HU \\ School of Civil Engineering and Architecture. East China \\ Jiao Tong University \\ ECJTU \\ Nan Chang, China \\ 383342936@qq.com \\ Hong-ling DAI \\ School of Civil Engineering and Architecture. East China \\ Jiao Tong University \\ ECJTU \\ Nan Chang, China \\ 12569825@qq.com
}

\begin{abstract}
The pre-oxidation agent is potassium permanganate $\left(\mathrm{KMnO}_{4}\right)$ and the adsorbent is powdered activated carbon in this experiment. The raw water is treated by $\mathrm{KMnO}_{4}$ comparing with $\mathrm{KMnO}_{4}$ and powdered activated carbon in order to study the removal of turbidity, algae and odor. When the $\mathrm{KMnO}_{4}$ dosage is $1.2 \mathrm{mg} / \mathrm{L}$, the removal rate of turbidity, chlorohyll(a) and odor are $75.3 \%, 76.2 \%, 68.2 \%$ respectively. When the dosage of $\mathrm{KMnO}_{4}$ and powdered activated carbon are $1.2 \mathrm{mg} / \mathrm{L}$ and $15 \mathrm{mg} / \mathrm{L}$ respectively. The removal rate of turbidity, chlorohyll(a), and odor are $90.3 \%, 92.7 \%, 91.9 \%$ respectively. The experimental results show that the process that $\mathrm{KMnO}_{4}$ combined with powdered activated carbon achieved more effective turbidity removal.
\end{abstract}

Keywords-potassium permanganate; powdered activated carbon; algae; odor; coagulation

\section{INTRODUCTION}

The meaning of water remediation technology[1-2] is to use physical, chemical and Biological method to decrease the concentration of toxic and harmful substance in the water, which leads to repair part, even whole water ecological environment so as to reach the requirement of water function.

Algae can secrete some odor causing substances such as olefine, fatty alcohol, aldehydes and thioether. And the algae sinking into bottle of tank rot easily, which results in fishy smell. Morever, some kinds of algae can create algal toxin[34].

Organic pollutant can stick to colloidal solids surface, increasing solids stability, decreasing their collision probability, so algae organic pollutant is going to hinder colloids sedimentation and destabilization. And most water treatment plants usually use general coagulation to dispose raw water containing algae. With simply increasing dosage, the sludge quantity is also increasing, which is disadvantage to remove algae, aggravating filter load, shorten backwash cycle and increasing cost[5].

Aiming these kinds of problems, this experiment compares $\mathrm{KMnO} 4$ and $\mathrm{KMnO} 4$ combined with powdered activcated carbon in algae water treatment.

\section{MATERIAL AND METHODS}

\section{A. Quanlity of Raw Water}

The raw water takes from Kongmu Lake in East China Jiaotong University. The turbidity is 7.750NTU. The chlorohyll(a) is $167.8 \mathrm{mg} / \mathrm{m} 3$. Olfact is 285.7 and $\mathrm{pH}$ is 7.4 .

\section{B. The Methon of Measure Water Index}

1) Turbidity: TDT-2 scattered light turbidimeter is used to measure water turbidity.

2) Olfact: After experiment, supernate is acquired and diluted by a certain volume of odorless water, then artificial smelling after heating $30 \mathrm{~min}$ under $(60 \pm 1)^{\circ} \mathrm{C}$. The olfact is a proportion that odor is stinking when odorless water is diluted to supernate. And the olfact is confirmed by five people, calculating by mean value method.

3) Chlorohyll(a): After experiment, $200 \mathrm{~mL}$ water sample is obtained and filtered by acetate cellulose membrane whose diameter is $0.45 \mu \mathrm{m}$, ground by $90 \%$ acetone to extract chlorohyll(a). Then it is centrifuged in $15 \mathrm{~min}$ on $4000 \mathrm{r} / \mathrm{min}$. Supernate is aquired to measure the absorbancy in spectrophotometer when the wave lengths are $750 \mathrm{~nm}, 663 \mathrm{~nm}, 645 \mathrm{~nm}$ and $630 \mathrm{~nm}$ respectively. 


\section{RESULTS AND DISCSSIONS}

\section{A. Coagulant Selection and Best Dosage}

After blending, these 1L water samples are injected severally into six same beaker in six-units stirring apparatus, stirring quickly $0.5 \mathrm{~min}$ under $320 \mathrm{r} / \mathrm{min}$, stirring intermediately $8 \mathrm{~min}$ under $170 \mathrm{r} / \mathrm{min}$ with 6 kinds of coagulation condition $(15,20,25,30,35,40 \mathrm{mg} / \mathrm{L})$, and stirring slowly $10 \mathrm{~min}$ under $80 \mathrm{r} / \mathrm{min}$, standing $30 \mathrm{~min}$ before taking $2 \mathrm{~cm}$ supernate to measure.

Coagulation mixing experiments are cunducted to three kinds of coagulants such as aluminium polychlorid, aluminum sulfate and ferric trichloride. Fig. 1, 2 and 3 respectively show the index and removal effect.

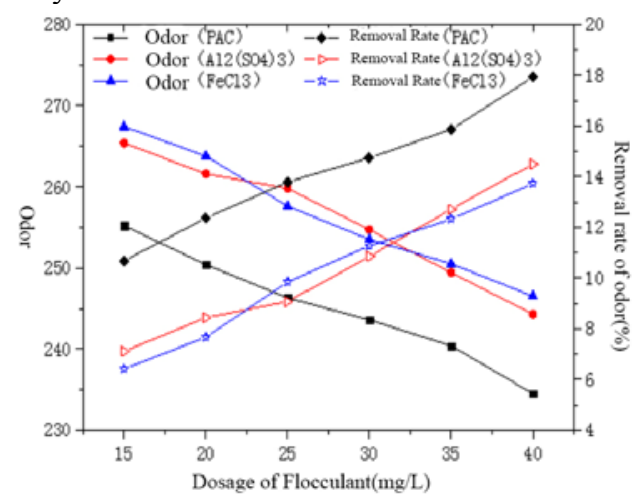

Figure 1. Effect of different coagulants dosage on removal rate of turbidity.

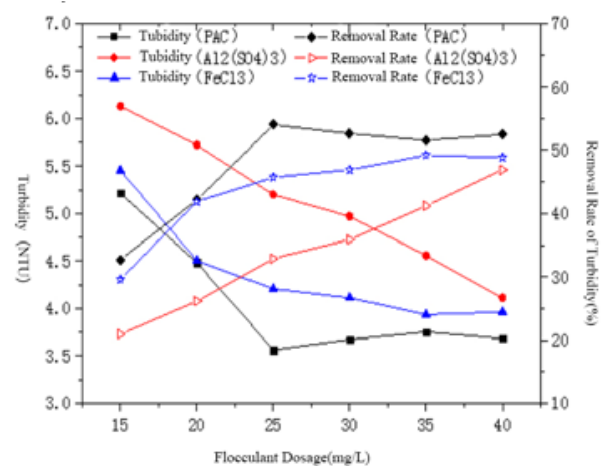

Figure 2. Effect of different flocculant dosage on removal rate of chlorohyll(a)

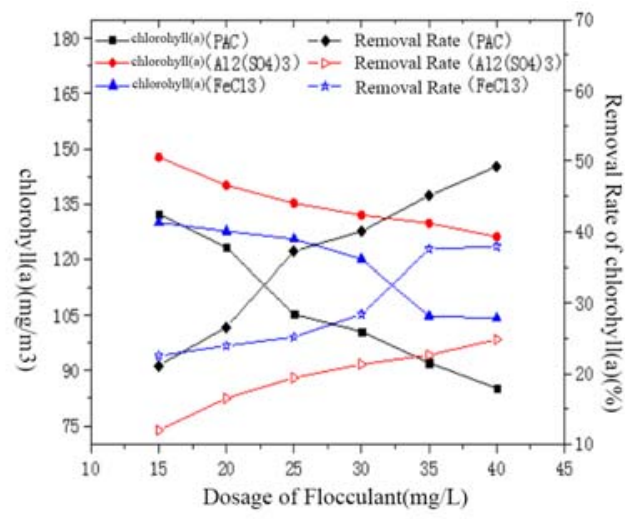

Figure 3. Effect of different flocculant dosage on removal rate of odor

Comparing and analyzing the effect of three kinds of coagulant, it can be known that aluminium polychlorid is better than aluminum sulfate and iron trichloride in turbidity, chlorohyll(a) and odor removal. And the best dosage of these three kinds of coagulants, aluminium polychlorid, aluminum sulfate and iron trichloride, are $25 \mathrm{mg} / \mathrm{L}, 40 \mathrm{mg} / \mathrm{L}$ and $35 \mathrm{mg} / \mathrm{L}$ respectively. By this time, the removal of turbidity are $54.0 \%$, $46.9 \%$ and $49.2 \%$ while removal of chlorohyll(a) are $37.3 \%$, $24.9 \%$ and $37.5 \%$, and the removal of odor are $13.8 \%$, $14.5 \%$ and $13.7 \%$. Considering the experimental effect and cost, the best coagulant is aluminium polychlorid, and its dosage is $25 \mathrm{mg} / \mathrm{L}$.

\section{B. $\mathrm{KMnO}_{4}$ Pre-oxidation Experiment}

The 1L water samples are injected severally into six same beaker in six-units stirring apparatus, stirring slowly $15 \mathrm{~min}$ under $60 \mathrm{r} / \mathrm{min}$ with $0.8,1.2,1.6,2.0$ and $2.4 \mathrm{mg} / \mathrm{L}$ $\mathrm{KMnO} 4$, stirring quickly $0.5 \mathrm{~min}$ under $320 \mathrm{r} / \mathrm{min}$. And then aluminium polychlorid is put into it with intermediate stirring $8 \mathrm{~min}$ which is $170 \mathrm{r} / \mathrm{min}$ before slow stirring $10 \mathrm{~min}$ with $80 \mathrm{r} / \mathrm{min}$, standing $30 \mathrm{~min}$ before taking $2 \mathrm{~cm}$ supernate to measure. Fig. 4 presents the removal effect.

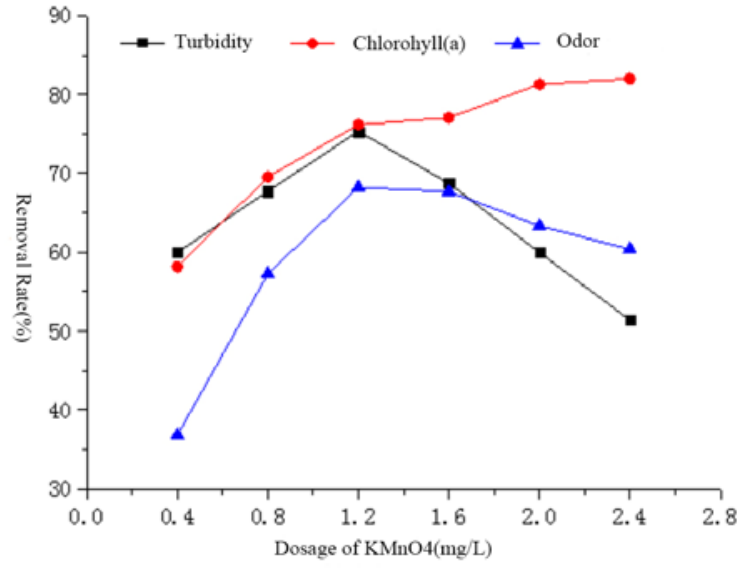

Figure 4. Effect of dosage of potassium permanganate on removal rate of water quality indexes

When the dosage of $\mathrm{KMnO} 4$ is increasing from 0.4 to $1.2 \mathrm{mg} / \mathrm{L}$, the removal of turbidity is rising. And when its 
$1.2 \mathrm{mg} / \mathrm{L}$, the removal is best by $75.3 \%$, and the turbidity is $1.914 \mathrm{NTU}$. The main reason is that the strong oxidizability of $\mathrm{KMnO} 4$ can inactivate algae to promote flocs destabilization, enhancing the diameter and velocity so as to improve algae removal effect. When the dosage is over $1.2 \mathrm{mg} / \mathrm{L}$, the turbidity removal is decreasing because the rest of $\mathrm{KMnO} 4$ leaves in the water to create chroma and disturb indirectly turbidity measure.

With increasing the dosage of $\mathrm{KMnO} 4$, its pre-oxidation can inactivate algae to easily form flocs to settle, so that the algae can be removed[7]. When the dosage of $\mathrm{KMnO} 4$ is $1.2 \mathrm{mg} / \mathrm{L}$, the removal rate of chlorohyll(a) is $76.2 \%$. Meanwhile, the chlorohyll(a) is $40 \mathrm{~m} / \mathrm{m} 3$. While $\mathrm{KMnO} 4$ dosage is over $1.2 \mathrm{mg} / \mathrm{L}$, the rate is slightly increasing.

When the dosage of $\mathrm{KMnO} 4$ is $1.2 \mathrm{mg} / \mathrm{L}$, the removal rate of odor is $68.2 \%$. Its removal mainly rely on strong oxidizability of $\mathrm{KMnO} 4$ and the adsorption of the intermediate products in reaction[8]. The range of $\mathrm{KMnO} 4$ dosage is from 1.2 to $2.4 \mathrm{mg} / \mathrm{L}$, and the exceeding $\mathrm{KMnO} 4$ can oxidize the odourless matter to odour matter, oxidizing the macromolecule odour matter to the micromolecule so as to increase olfact[9-10]. Considering various factors, the best $\mathrm{KMnO} 4$ dosage is $1.2 \mathrm{mg} / \mathrm{L}$.

\section{The Experiment of KMnO4 Combined with Powdered Activated Carbon}

The 1L water samples are injected severally into six same beaker in six-units stirring apparatus, stirring slowly $15 \mathrm{~min}$ under $60 \mathrm{r} / \mathrm{min}$ with $1.3 \mathrm{mg} / \mathrm{L} \mathrm{KMnO} 4$, then stirring quickly $0.5 \mathrm{~min}$ under $320 \mathrm{r} / \mathrm{min}$. The $25 \mathrm{mg} / \mathrm{L}$ floculant and powdered activated carbon $(5,10,15,20,25$ and $30 \mathrm{mg} / \mathrm{L})$ are injected, stirring intermediately $8 \mathrm{~min}$ under $170 \mathrm{r} / \mathrm{min}$, and then stirring slowly $10 \mathrm{~min}$ under $80 \mathrm{r} / \mathrm{min}$, standing $30 \mathrm{~min}$ before taking $2 \mathrm{~cm}$ supernate to measure.Fig. 5 presents the removal effect.

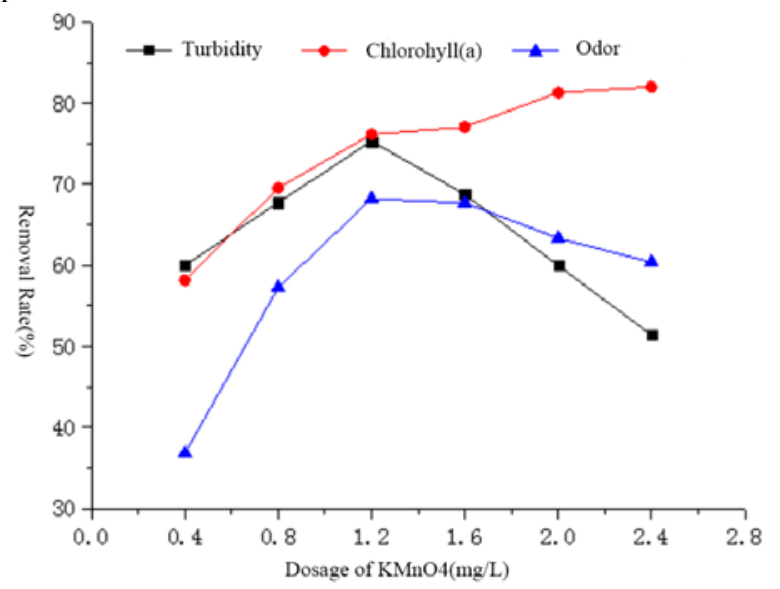

Figure 5. Effect of dosage of powedered activated carbon on removal rate of water quality indexes

With increasing the dosage of powedered activated carbonm, the removal rate is increasing followed by decreasing. The removal rate of chlorohyll(a) and odor rises steeply beteween 5 and $15 \mathrm{mg} / \mathrm{L}$. And when the dosage is over $15 \mathrm{mg} / \mathrm{L}$, the extent decreases relatively. When the dosage is $15 \mathrm{mg} / \mathrm{L}$, the removal rate of turbidity, chlorohyll(a), and odor are $90.3 \%, 92.7 \%, 91.9 \%$ respectively.

The KMnO4 oxidation technology possesses boundedness, for example, the manganese concentration in outlet is not controlled easily and the turbidity is high. It can adequately bring into play the former oxidability and latter adsorption that combines $\mathrm{KMnO} 4$ with powdered activated carbon. $\mathrm{KMnO} 4$ can decrease the electronegativity in particle surface and repulsive interaction of double electrode layer so as to destabilize and settle easily.

Meantime, the organic matter is going to oxidize and polymerize in the powedered activated carbon to improve its adsorption. The specific surface area of powedered activated carbon is big, and the pre-oxidation algae lose activity, which is advantage to be absorbed by activated carbon. The powedered activated carbon is a special reducive substance, accelerating to produce $\mathrm{KMnO} 4$ oxidative product which is new ecological hydrated manganese dioxide, preventing the overproof of manganese concentration in outlet. And the role of manganese dioxide is oxidation and adsorption[1112].

Considering all elements, the best dosage of powdered activated carbon is $15 \mathrm{mg} / \mathrm{L}$.

\section{Experimental Result Comparison}

The Fig. 6 shows the experimental result comparison of different technology.

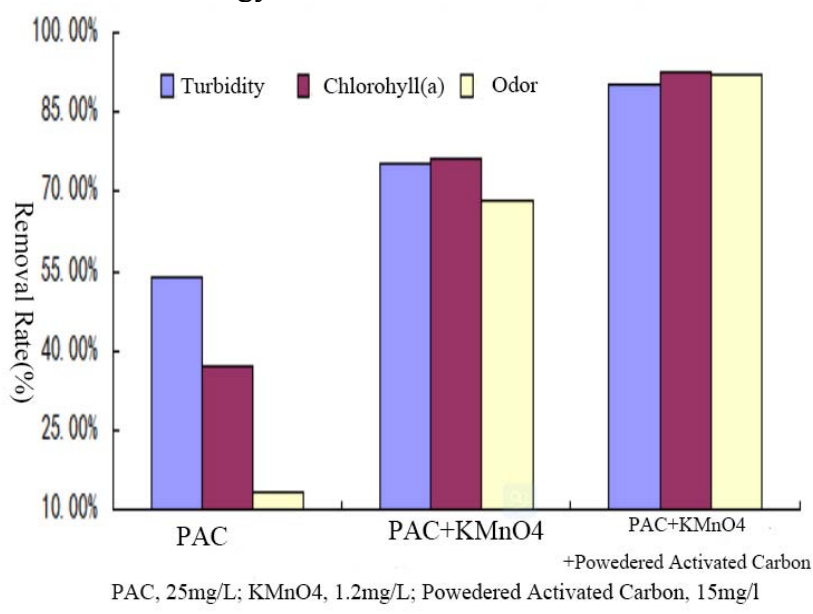

Figure 6. Contrast of the Processes Test Results

Comparing the experimental results of different technology, it can be known that $\mathrm{KMnO} 4$ combined with powedered activated carbon can better to dispose algae raw water, which can decrease algae content and remove odor to reach water ex-situ remediation.

\section{CONCLUSION}

1) Comparing aluminum sulfate and ferric chloride, aluminium polychlorid is more effective in coagulation. But it is poor effect on odor and algae water treatment that coagulant is only injected, which can slightly remove algae, but not effective to odor. 
2) Using $\mathrm{KMnO} 4$ to pre-oxidate raw water, it can decrease effectively turbidity and algae content, and remove part of odor. When the dosage of $\mathrm{KMnO} 4$ is $1.2 \mathrm{mg} / \mathrm{L}$, the removal rate of turbidity, chlorohyll(a) and odor are $75.3 \%$, $76.2 \%$ and $68.2 \%$ respectively.

3) It owns Complementarity and cooperativity that KMnO4 combines with powdered activated carbon to dispose raw water. And when the dosage of $\mathrm{KMnO} 4$ and powdered activated carbon are $1.2 \mathrm{mg} / \mathrm{L}$ and $15 \mathrm{mg} / \mathrm{L}$, the removal rate of turbidity, chlorohyll(a) and odor are $90.3 \%$, $92.7 \%$ and $91.9 \%$ respectively.

4) When the $\mathrm{KMnO} 4$ combined with powdered activated carbon, the removal rate of turbidity, chlorohyll(a) and odor are $36.3 \%, 55.4 \%$ and $78.1 \%$ more than those with conventional water treatment technology. Meanwhile, it also offers technical support for pollutional lake water ex-situ remediation, repairing water ecological setting, satisfied the requirement of sustainable development.

\section{ACKNOWLEDGMENTS}

This work is supported by National Nature Science Foundation of China (No.61640217); Science and Technology Support Program of Jiangxi Province (No.20161BBI90033); Landing Plan of Scientific and Technological Project of Jiangxi Provincial Colleges and Universities(No.KJLD2013037); Cultivation Plan of Leadership for Excellence Jiangxi Province and Poyang Lake 555 Engineering (S2013-57).

\section{REFERENCES}

[1] X. Z. Mao, A. Gui, Y Tao, X H Zhang, "Investigation on effect of treatment units in restoration project for urban lakes - a case study of Lake Lichee in Shenzhen,” J. Lake Sci., vol. 4, 2008, pp. 456-462.
[2] W. L. Dong, S. F. Ming, J. F. Yang, M. M. Yao, "Research on countermeasures to prevent and control lakes eutrophication," Environmental Science and Management, vol. 11, 2014, pp. 82-85.

[3] N. Y, Gao, Y Ma, W H Chu, "Integration and demonstration of the water treatment technologies for the raw water heavily polluted by aglae and organic from lake reservoir," Water\&Wastewater Engineering, vol. 3, 2013, pp. 13-16.

[4] R. B. Jia, X. H. Zhang, W. H. Zhang, G. M. Zhang, Z. S. Wang, "Fluctuation of microcystins in water plant," Journal of environmental science and Health(partA), vol. 12, 2003, pp. 2867-2875.

[5] P. N. Owens, D. E. Walling, "The phosphorus content of fluvival sedimentation in rural and industriali-zed river basins", Water Research, vol. 3, 2002, pp.685-701.

[6] B. Yue, Y. Yan, M. P. Xie, L. Li, T. Lin, "Treatment of enhanced coagulation process of potassium permanganate pre -oxidation for raw water with high-algae," Water Purification Technology, vol. 2, 2013. Pp. 16-19.

[7] J. J. Chen, H. H. Yeh, "The mechanisms of potassium permanganate on algae removal," Water Research, vol. 18, 2005, pp. 4420-4428.

[8] Z. Y. Yuan, X. Q. Li, H. Zhang, "Experimental study on potassium permanganate deodorization technology," China water\& Wastewater, vol. 15, 2009, pp. 63-66.

[9] Q. X. Zhen, "Control of algae in treatment of drinking water," China water\& Wastewater, vol. 17, 2010, pp. 98-100.

[10] X. Y. Ma, Z. H. Zhang, H. Y. Wang, S. F. Hu, Q. S. Li, "Simultaneous removal of algae and its odorous metabolite dimethyl trisulfide in water by potassium ferrate," Environmental Science, vol. 5, 2013, pp. 1767-1772.

[11] Y. L. Pang, "Study on the use of potassium permanganate in combination with powder activated carbon for the removal of taste and odor in drinking water. Beijing: Beijing University of Technology, 2011

[12] G. T. Xie, M. Chao, H. Xu, X. F. Hu, W. Ding, "Odor removal in raw water by potassium permanganate combined with powdered activated carbon," Water Technology, vol. 2, 2012, pp. 1- 